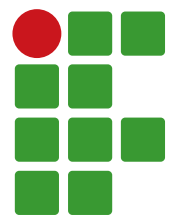

\title{
Estimating of the vibration levels for truck transport in Iran
}

\author{
${ }^{1}$ Department of Biosystems Engineering, University of Tabriz. PhD Student. ramezani.boukat@gmail.com. \\ ${ }^{2}$ Department of Biosystems Engineering, University of Tabriz. Associate Professor. navid@tabrizu.ac.ir. \\ 3 Department of Communications Engineering, University of Tabriz. Associate Professor. niya@tabrizu.ac.ir. \\ 4 Department of Communications Engineering, University of Tabriz. PhD Student. sajjadranjbar88.5@gmail.com
}

Received in: January 30, 2021 | Accepted in: July 02, 2021

\section{Abstract}

A wide-ranging of distribution environments could affect designing packages. The first step in the proper packaging design of agricultural products, particularly fruit, is to conduct a precise simulation of the truck transport. Thus, this research was conducted to analyze the vibration levels for truck transport using multi-sensor-based computing on packaged fruit in Iran (the first), one of the leading agriculture in Middle East Asia. Towards this goal, a wireless sensor network made of three sensor nodes with tri-axial accelerometers was designed to measure the vibration levels for truck transport at three package locations equipped with leaf-spring suspension in local and highway roads. To measure the vibration data a power spectral density function (PSD) levels were applied. Compared to the International Standards (ASTM 4728: West Conshohocken, USA, ISTA: Chicago, USA), the PSD levels of the truck in both roads types were higher in 1 to $35 \mathrm{~Hz}$, and lower in 35 to $200 \mathrm{~Hz}$. In particular, the differences in directional vibration levels were more pronounced in the low-frequency range of $10 \mathrm{~Hz}$ in both road types. The highest amount of truck bed acceleration occurred in the packages located at the rear end of the trucks. And, the peak PSD values were obtained as equal to $0.178 \mathrm{G}^{2} / \mathrm{Hz}$ (rear-up), $0.136 \mathrm{G}^{2} / \mathrm{Hz}$ (rear-down), and $0.096 \mathrm{G}^{2} / \mathrm{Hz}$ (front-up) locations, respectively. Meanwhile, the road quality had affected the vibration levels in such a way that the peak PSD value obtained on highways was lower than that of the ones of the local roads. According to the results, the amount of acceleration on the heavy truck beds on the country's roads can be considered $0.654 \mathrm{G}$. In sum, the current results can be used to simulate the truck transport conditions by programmable vibration simulators to reproduce the vibration conditions for package testing in Iran roads. And, the findings are of high interest to improve packaging design, reduce fruit damage, maintain shelf life, smart transportation, and related industries.

Keywords: Fruit vibration. Power spectral density. Truck transport. Roads. Iran.

\section{Introduction}

The transportation system is globally one of the most significant and well-known industries. In general, this involves various complexities either visible or invisible. The complexities of such an important sector could facilitate globally and locally by the combination of available information technologies such as global positioning system (GPS) and wireless sensor network (WSN) to provide complete monitoring information (RUIZ-GARCIA et al., 2007).

The crop's quality after the harvest cannot be improved, but it could be maintained (BACHMANN; EARLES, 2000). Thus, the globalization of fresh produce trade needs better long-distance transportation systems to deliver high-quality products to the consumer (VIGNEAULT et al., 2009). Vibration during road transport by trucks is the main cause of mechanical damage to fresh agricultural products, in the post-harvest stage (GEBRESENBET et al., 2011). Many studies have investigated the magnitude of mechanical damage caused by the vibration of transportation for fruit (ISHIKAWA; KITAZAWA; SHIINA, 2009; YENGE; NIDONI, 2014; SPRINGAEL; PATERNOSTER; BRAET, 2018). Poor driving performance, road features, package features, truck features, package location, and fruit features are the main factors causing vibration (ZHOU; SU; LI, 2007; RANATHUNGA et al., 2010; ZHANG et al., 2011). 
Vibration simulation testing is based on the assessment of the effect of vibration parameters during transportation on agriculture products. This simulation test protocol saves time and makes possible the assessment of the performance of different packaging or cushioning methods in fruit transportation (WASALA et al., 2015). Some globally standardized test protocols like ASTM, ISTA, and JIS (LU et al., 2010b) indicate the power spectral density function (PSD) levels for vibration simulation test of transportation. A PSD function shows the strength of the variations (energy) as a function of frequency. Broadly, it shows at which frequencies variations are strong and weak. Based on recent data obtained in South Korea (September 27, 2020) the PSD function is still widely used because accelerated test conditions can be easily generated from the PSD acquired from a particular transport section (PARK; CHOI; JUNG, 2020). Measured vibration levels can be used to program and configure vibration equipment at the laboratory to reproduce these vibration conditions (RISSI et al., 2008), and to develop test methods for the evaluating of packages (CHONHENCHOB et al., 2009). Some past studies have mentioned the growth of protective packaging systems to minimize fruit damage occurring during road transport. Relatively few studies were published after the outset-2000s. And, estimation of truck vibration levels has been already studied in some countries such as India (SINGH et al., 2007), Japan (LU et al., 2008), Brazil (RISSI et al., 2008), Spain (GARCIA-ROMEU-MARTINEZ; SINGH; CLOQUELL-BALLESTER, 2008), Thailand (CHONHENCHOB et al., 2010), China (ZHOU; WANG, 2018), and Korea (PARK; CHOI; JUNG, 2020) to develop a database to define a 'distribution environments around the Globe'.

In Iran, one of the leading agriculture in the Middle East Asia, trucks play a significant role in the transportation of agricultural products due to the usual long distances between orchards and consumers. The total length of the country's roads in 2018 was about $88,000 \mathrm{~km}$. For each $100 \mathrm{~km}$ of intercity, there is $22 \mathrm{~km}$ of freeways and highways. Despite the importance of this section and the extent of the country, no noticeable study has been done to investigate the vibration analysis during packaged fruit transporting using mounted sensors. Meantime, based on our knowledge until now there was no research related to PSD development by transport routes of the truck in Middle East Asia, particularly in Iran. Therefore, the objective of this study was to estimate: 1 ) truck vibration levels and indicating the predominant frequency based on PSD spectrums; 2) influential factors, and 3) the root mean square acceleration (RMS) to provide packaging designers with accurate information on the country's road status. Finally, the sum of the parameters affecting the truck vibration levels, such as truck speed, and location of the package in the longitudinal direction of the truck, were evaluated.

\section{Material and methods}

\section{Sampling}

This research included two types of sampling: 1) under controlled conditions, to investigate the effectiveness of each parameter on truck vibration levels by keeping constant the remainder parameters. In this case, the effect of driving speed (maximum and minimum) and roads type (local and highways) on truck vibration levels were investigated (under the same conditions); 2) in real condition with the usual transportation speed in Iran, which aimed to obtain the predominant frequency of the country's roads to be used (for example in laboratory vibration tests). In this case, the acceleration levels were measured in lateral, longitudinal, and vertical directions in two roads type (local and highways) according to the actual driving 
speeds in Iran $(70-90 \mathrm{~km} / \mathrm{h})$. By randomly sampling the acquired data, the results were represented using PSD diagrams, and the influential factors in truck's vibration levels transport were studied.

\section{Vehicle and routes}

The vibration levels measurement was carried out on three trucks with leaf-spring suspension. Table 1 presents details of the trucks, packaging, and routes used in the study.

Table 1 - Truck features and details of the packaging, and routes for vibration levels measurement.

\begin{tabular}{cccc}
\hline Truck ID & $\mathbf{1}$ & $\mathbf{2}$ & $\mathbf{3}$ \\
\hline Brand & Benz Axor & Foton & Benz Axor \\
Suspension type & Leaf-spring & Leaf-spring & Leaf-spring \\
Tire model & $315 / 80$ R22.5 & $235 / 7.5$ R17.5 & $315 / 80$ R22.5 \\
Load capacity (kg) & 10000 & 4000 & 10000 \\
Package type & RPCa & RPC & RPC \\
Route & Tabriz-Karaj & Maragheh-Tehran & Shiraz-Birjand \\
Distance $(k m)$ & 550 & 600 & 1000 \\
Road type & Local \& Highway & Local \& Highway & Local \& Highway \\
\hline
\end{tabular}

a Reusable Plastic Crates (490*300*190 $\mathrm{mm}^{3}$ )

Source: Elaborated by the authors (2019).

The three selected routes represent different roads type in Iran. The reason for sampling the data acquired in the long route was to obtain information from different geographical locations of the country's roads. Figure 1 shows the traversed paths, and Figure 2 depicts the condition of two studied roads, i.e., local and highway roads in the study.

Figure 1 - Truck transportation routes investigated in Iran.

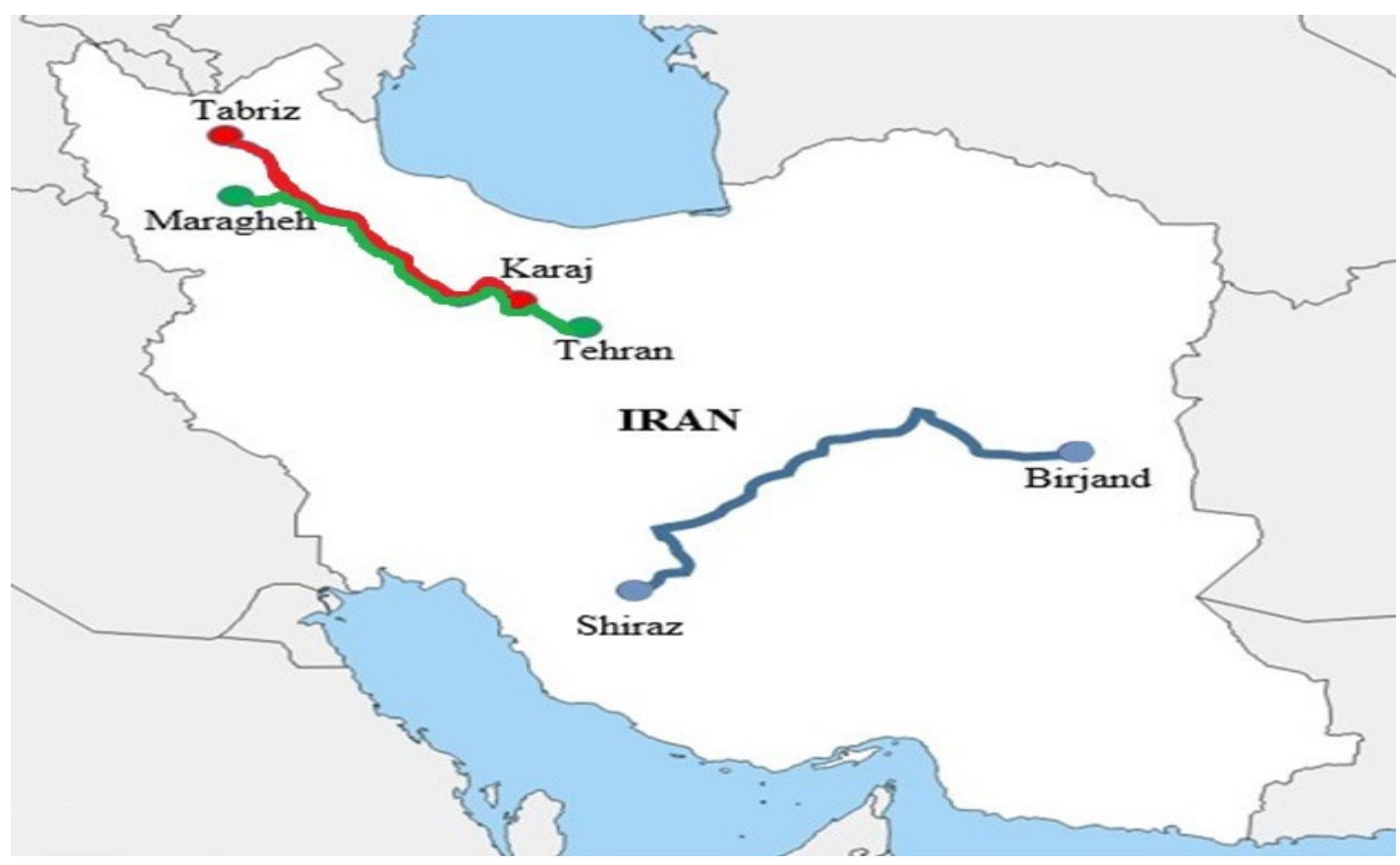

Source: Elaborated by the authors (2019). 
Figure 2 - Roads type: local (left), and highway (right).
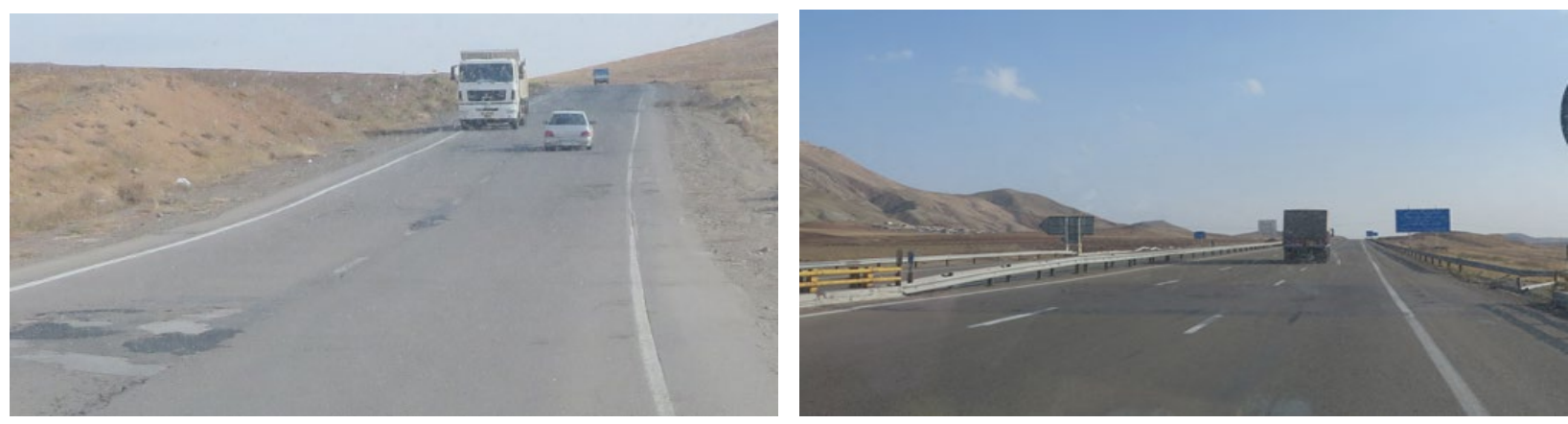

Source: Elaborated by the authors (2019).

\section{Measuring instruments}

Figure 3 shows the used real-time monitoring system, the measuring instruments, and the data acquisition scheme on the truck. This arrangement made it possible to study the difference between the acceleration levels in the longitudinal and vertical directions of the truck. A WSN with three sensor nodes and a base station was used to measure the acceleration of the truck under analysis. A GPS receiver (VK-162 Gmouse USB GPS, China), and a laptop (Acer, V3-571G) were used to determine the location of the truck and data analysis, respectively.

This WSN solution enabled the sensors to be easily mounted at different locations and provide real-time data monitoring. Additionally, the results were compared among the different locations of each truck. Each node of the WSN consisted of the following four components:

- Sensor (A tri-axial accelerometer-ADXL 345, \pm 4 g ranges, Analog devices).

- Microcontroller (Texas instrument ARM Cortex-M3 embedded in CC2538).

- Radio transceiver (2.4 GHz ZigBee transceiver embedded in CC2538).

- Power supply (4V external battery with an LDO linear regulator).
The acquired data can be used in laboratory vibration tests if is independent of the fruit type. Because the acceleration of the truck bed, unlike the one at top rows, does not depend on the fruit type and the acceleration at the end of the truck is higher than at the front, the current study focused on the vibration at the end of the truck bed (according to previous studies). This data was used in the subsequent calculations to obtain the PSD spectrums and the predominant frequency that is independent of the fruit type and packages height and can be used as a reference to simulate vibration.

WSN was established using a ZigBee protocol working at a $2.4 \mathrm{GHz}$ ISM frequency band to communicate with the receiver board. A CC2538 IC was configured by an ARM microcontroller and a radio transceiver in $2.4 \mathrm{GHz}$. The implemented code of each node was programmed on the ARM microcontroller, which is composed of an internal radio transceiver for data transmission. The ADXL accelerometers were used for the data sampling and connected to the ARM existing on the CC2538 IC by an I2C port. The base station was configured as a receiver node. The address of the receiver node was embedded into the other nodes (transmitter nodes). Each of these nodes transmitted the sampled information to the receiver node, which forwarded the received data to the computer system through the USB port, Figure 4. 
Figure 3 - Estimating the fruit truck's vibration levels transport using wireless sensor network (a base station linked with a USB port and three sensor nodes), GPS; module linked with a USB port and a real-time monitoring system to accurately follow-up the collected data, and the laptop was used to record the acceleration values and to real-time monitoring the vibration in the driver cabin.

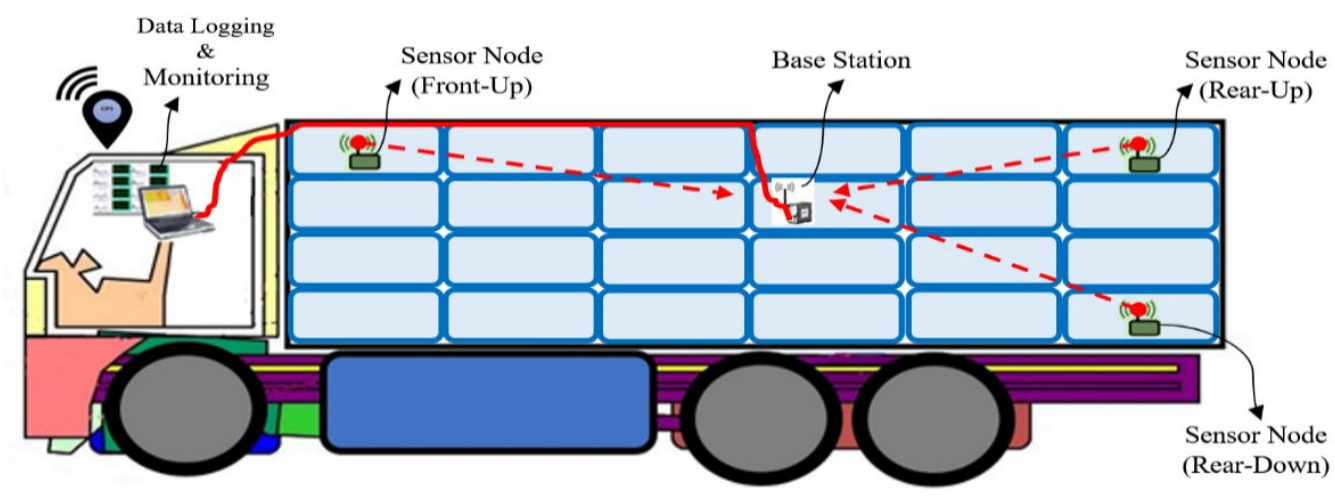

Source: Elaborated by the authors (2019).

Figure 4 - Measuring instruments: (a) sensor nodes, (b) base station, and (c) GPS receiver.

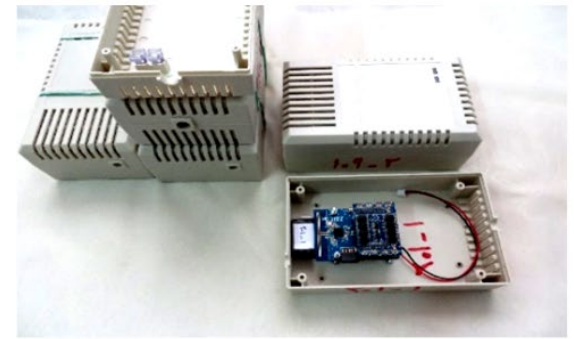

(a)

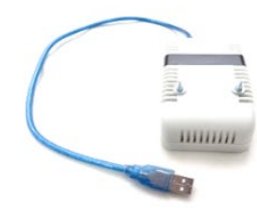

(b)

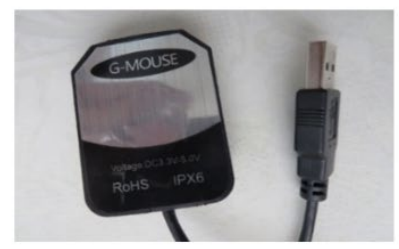

(c)

Source: Elaborated by the authors (2019).

The software code was developed in $\mathrm{C}++$ to receive the data from the USB port, and save the results in a formatted file. Due to the longtime data collection in each route (more than $10 \mathrm{~h}$ ), it was essential to reduce the power consumption. Thus, power management methods of network software design and data transmission as Time Division Multiple Access (AKYILDIZ et al., 2002) were applied. Using the software, it was also possible to start, stop, and control the data acquisition process from the driver's cab.

The interface of the custom-developed software used for the data gathering and real-time monitoring of acceleration resulting from the road vibration is presented in Figure 5.

\section{Data analysis}

A sample of the vertical vibration data for a $60 \mathrm{~s}$ period is presented in Figure 6, which shows the acceleration range that occurred in the rear of the truck bed used to determine the predominant frequency.

The data obtained from the nodes were partitioned according to $2.56 \mathrm{~s}$ regular intervals. After a random sampling of the data, the samples were analyzed in MATLAB 2015b. Lu et al. (2010b) suggested that truck vibration has a normal distribution and follows a Gaussian distribution. Thus, truck vibration is usually evaluated based on RMS, or PSD values. 
Figure 5 - The interface of the software written in $\mathrm{C}++$ for data gathering, and real-time monitoring of acceleration, including the window for the mini GPS receiver.

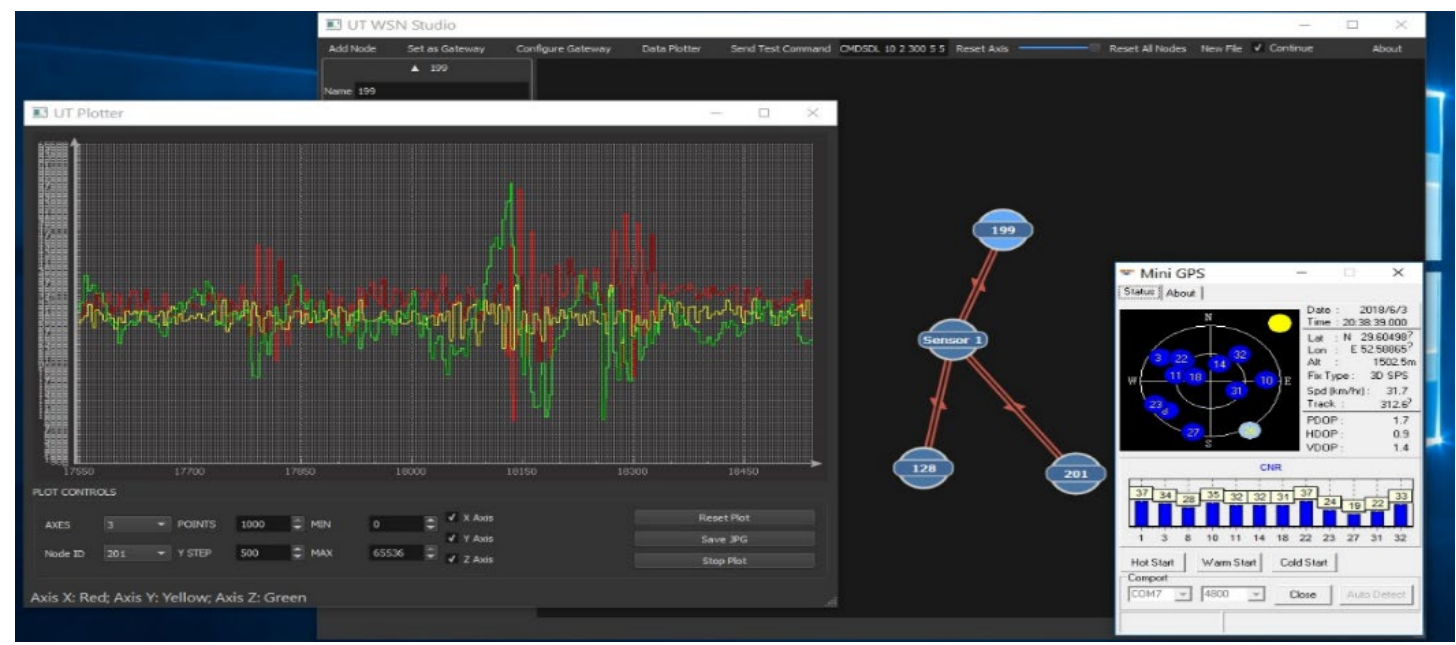

Source: Elaborated by the authors (2019).

Figure 6 - Vertical acceleration data from the sensor node located rear-down of trucks.

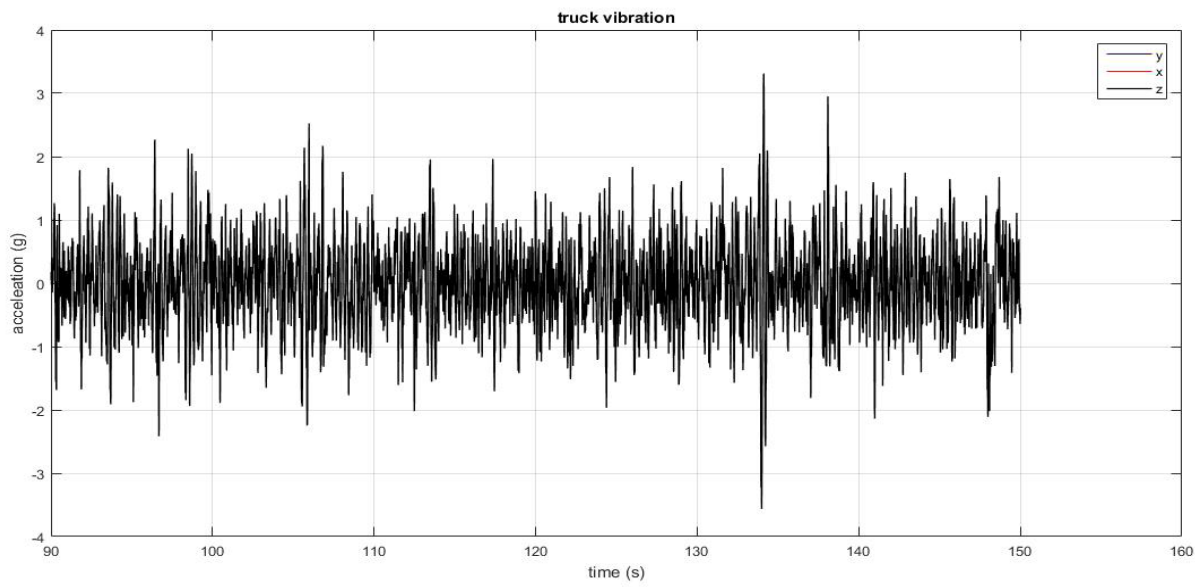

Source: Elaborated by the authors (2019).

The RMS level of a vector $G_{i}$ can be written as (ZHOU; WANG, 2018):

$$
\mathrm{RMS}_{\mathrm{G}}=\sqrt{1 / \mathrm{M} \sum_{\mathrm{i}=1}^{\mathrm{M}} \mathrm{G}_{\mathrm{i}}{ }^{2}}
$$

At which: $M$ is the number of $G$ samples, and $G_{i}$ is the acceleration of sample i.

The PSD spectrums are used as a function of frequencies during transportation. The PSD spectrums within a narrow band of frequencies can be constructed for each trip according to:

$$
\operatorname{PSD}=1 / \mathrm{BW}_{\mathrm{i}=1}^{\mathrm{n}}\left(\mathrm{RMS}_{\mathrm{G}_{\mathrm{i}}}{ }^{2}\right) / \mathrm{N}
$$

At which: PSD is the power spectral density function $\left(\mathrm{G}^{2} / \mathrm{Hz}\right), \mathrm{N}$ stands for the number of samples, $\mathrm{RMS}_{G}$ is the root mean square acceleration value and BW is the bandwidth of frequencies (RISSI et al., 2008).

In this study, $\mathrm{RMS}_{\mathrm{G}}$ and PSD spectrums were calculated for the random samples, and three 
peak values of each PSD graph with the corresponding frequency were recorded. The PSD estimations were obtained using the Fast Fourier Transform in MATLAB R2015b. Based on the suggestion made in prior studies, the sample rate $\left(F_{s}\right)$ and sample size $(N)$ were considered equal to $400 \mathrm{~Hz}$ and 1024 , respectively.

\section{Results and discussion}

\section{Truck's vibration levels in different directions}

There were few recent studies of the shock and vibration associated with the normal conditions of truck transport. In the case of the absence of data on the vibration damage on fruit, the simulation of the transport vibration levels under laboratory conditions can be helpful in the investigation of effective packing parameters. For such a big country, there was neither study on vehicle vibration measurement for a long route nor using a wireless sensor network with integrated sensors. Thus, for the first time in Iran, a WSN was utilized to measure the real-time acceleration of a truck to monitor vibration during fresh produce transportation in the current study. The main interesting aspects of the current study: long-term data acquisition and recording, analysis of long routes, processing on-the-go of 3D data, usage of data from a GPS, real-time data monitoring, employment of a WSN to cover different data acquisition points simultaneously, which led to high robustness of the results and findings.

Figure 7 represents the samples of acceleration in the three axes for the three trucks during transportation. The acceleration in the vertical direction is more critical than in the longitudinal and lateral directions.

Figure 7 - The tri-axial acceleration data of actual truck transport: (A) Truck 1, highway, rear-down; (B) Truck 2, local road, rear-down; and (C) Truck 3, highway, rear-down.
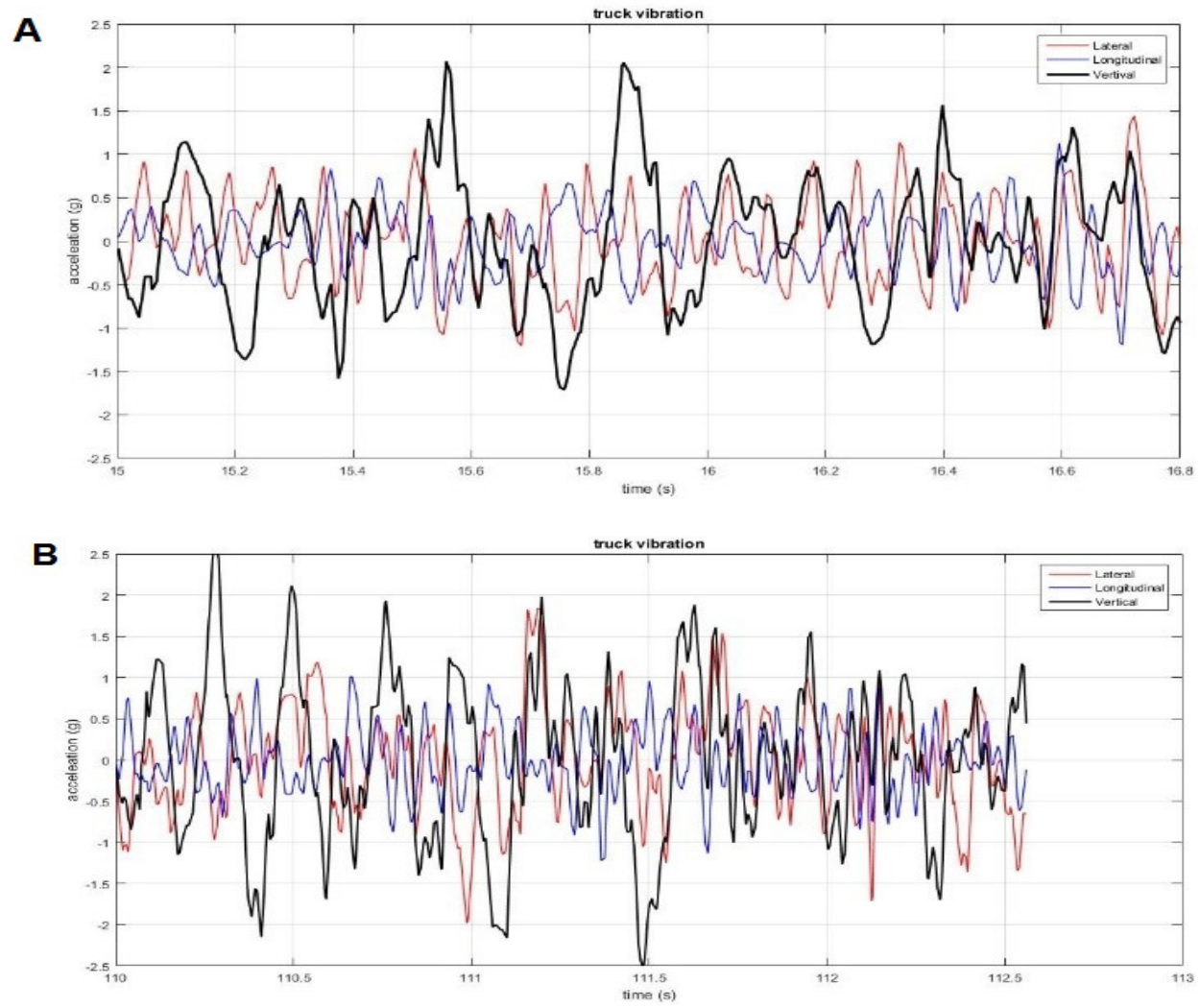


\section{C}

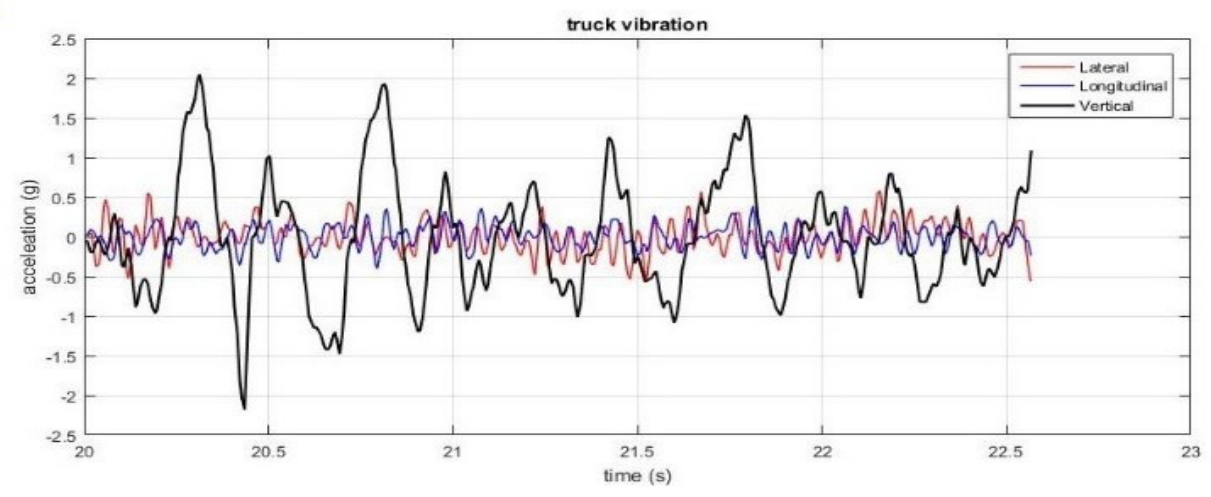

Source: Elaborated by the authors (2019).

In the same manner, PSD levels in the vertical direction are higher than the ones in the other directions below $10 \mathrm{~Hz}$ frequency ranges (FIGURE 8). Thus, the measured levels in vertical could be used in conjunction with longitudinal and lateral levels for packages and products that may not be perfectly cubed in the trailer and result in void spaces. In agreement with the present result, some authors observed various vibration levels of a truck in different directions (SINGH;
ANTLE; BURGESS, 1992; PARK; CHOI; JUNG, 2020). These authors concluded that the levels of vertical vibration are higher than the ones in the lateral and longitudinal vibrations at frequencies below $10 \mathrm{~Hz}$ (SINGH; ANTLE; BURGESS, 1992) and $110 \mathrm{~Hz}$ (PARK; CHOI; JUNG, 2020) in the same truck. Also, the lateral, longitudinal, and vertical spectrums had similar amplitude at frequencies higher than $10 \mathrm{~Hz}$.

Figure 8 - PSD spectrums for truck's vibration levels in longitudinal, lateral, and vertical axes: (A) Truck 1, highway, rear-down; (B) Truck 2, local road, rear-down; and (C) Truck 3, highway, rear-down.

A

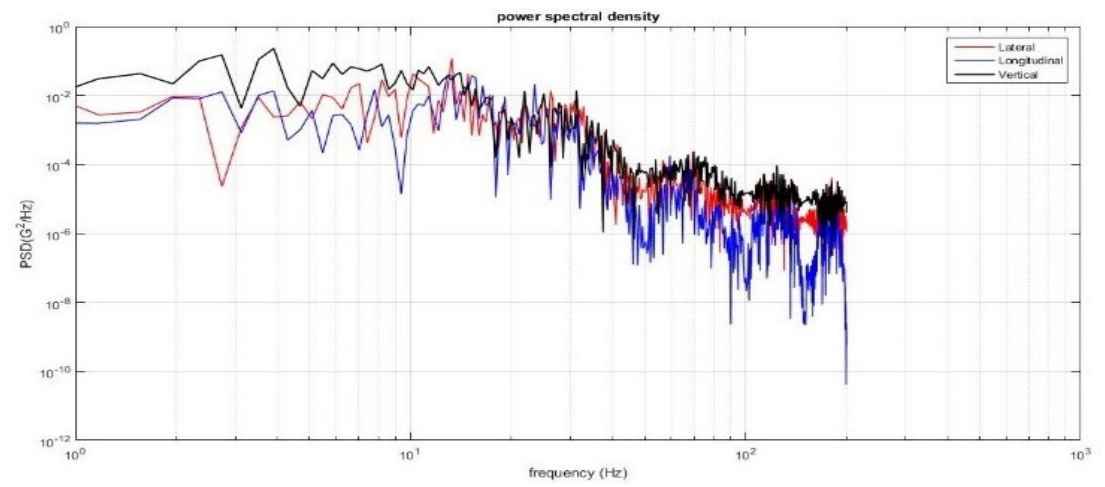

B

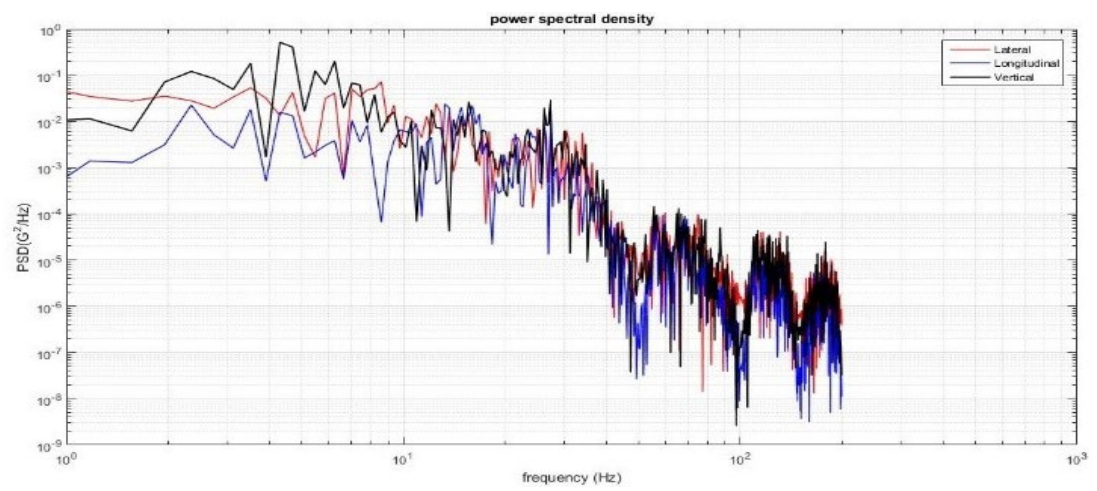




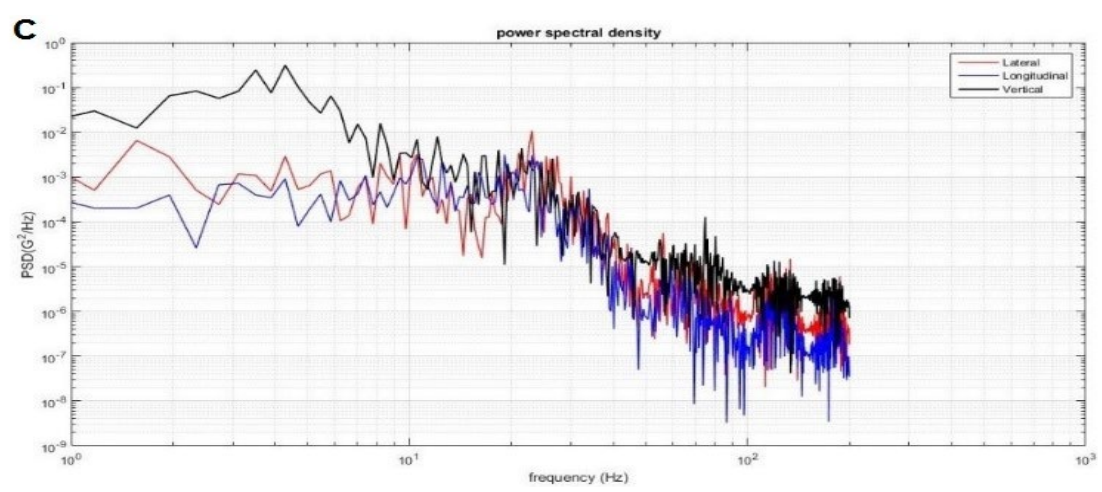

Source: Elaborated by authors (2019).

\section{Effect of package location on the truck's vibration levels}

Comparing the vibration intensities and their relationship to fruit damage helps to identify the influence factors in the mechanical damage and makes it possible to gather knowledge about actual transportation conditions. Broadly, vibration levels are influenced by other factors such as payload (SINGH; MARCONDES, 1992), cushioning material between the layers of fruit (AMER EISSA; ALBALOUSHI; AZAM, 2013), size, and variety of fruit (TABATABAEKOLOOR; HASHEMI; TAGHIZADE, 2013), and package type (VURSAVUŞ; ÖZGÜVEN, 2004). Therefore, understanding the causes of damage and vibration occurrence during truck transportation is vital to develop corrective procedures for the reduction of vibration damage (LU et al., 2010a).

A well-maintained road network is imperative for the distribution of freight forwarders in the modern world. In the present study, the results of vibration levels of the truck in different directions showed that in the longitudinal orientation of the trucks, the magnitude of the peak PSD in the rear location was higher than the one of the front locations (FIGURE 9A), which was also observed as to the other rows. Therefore, the highest amount of truck bed acceleration occurred in the packages located at the rear end of the trucks. In the vertical orientation of the same packages column, the vibration was higher in the upper row than that of the lower rows on the truck bed (FIGURE 9B). Peak PSD values were obtained as equal to $0.178 \mathrm{G}^{2} / \mathrm{Hz}$ for rear-up, $0.136 \mathrm{G}^{2} / \mathrm{Hz}$ for rear-down, and $0.096 \mathrm{G}^{2} / \mathrm{Hz}$ for front-up locations, respectively.

These findings agree with some previous experiments referring to in the same column, the vibration levels gradually increase from bottom to top in the low-frequency range (BOLLEN; TIMM; RUE, 2001; FERNANDO; FEI; STANLEY, 2019). Because the bottom packages are held by the packages above them, the freedom of movement of packages in the upper rows is greater than the bottom ones.

\section{Effect of truck speed and road condition on truck's vibration levels}

In general, trucks' vibration levels on national and international roads are usually weak, while on other routes are often improper such as in local and gravel roads. Moreover, cobblestones and concrete pavement generate a most severe vibration than asphalt roads during truck transport (PATERNOSTER et al., 2018). Figure 10 shows the PSD levels at two different speeds (70 and $90 \mathrm{~km} / \mathrm{h}$ ) under the same conditions, i.e., the same truck, road type, and location. It is worth mentioning to evaluate the effect of speed on vibration levels, the other parameters must be kept constant. The peak PSD values were equal 
Figure 9 - Vertical PSD spectrums of truck 3 at different locations simultaneously: (A) rear-up and front-up, and (B) rear-up and rear-down locations.
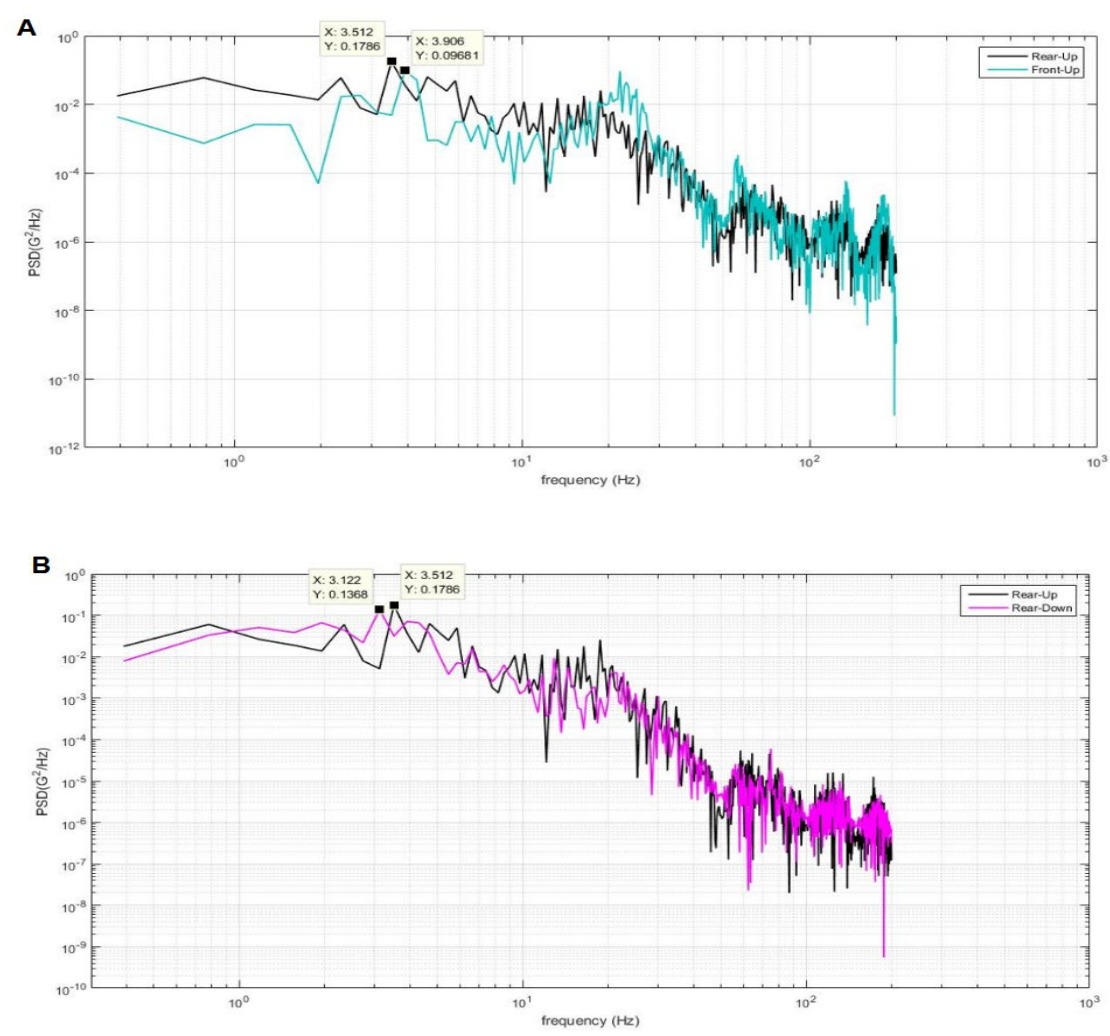

Source: Elaborated by authors (2019).

to 0.193 and $0.340 \mathrm{G}^{2} / \mathrm{Hz}$ for 70 and $90 \mathrm{~km} / \mathrm{h}$, respectively. It can be noticed that with the increase of the vehicle speed, the peak value of the PSD increased. Therefore, it is essential to use a driver awareness system to control vehicle speed according to the road conditions for vulnerable products transporting.

Figure 10 - The PSD spectrums of trucks' vibration levels in a vertical direction at $70 \mathrm{~km} / \mathrm{h}$ (in pink), and 90 $\mathrm{km} / \mathrm{h}$ (in black) (truck 3, highway, and rear-down location)

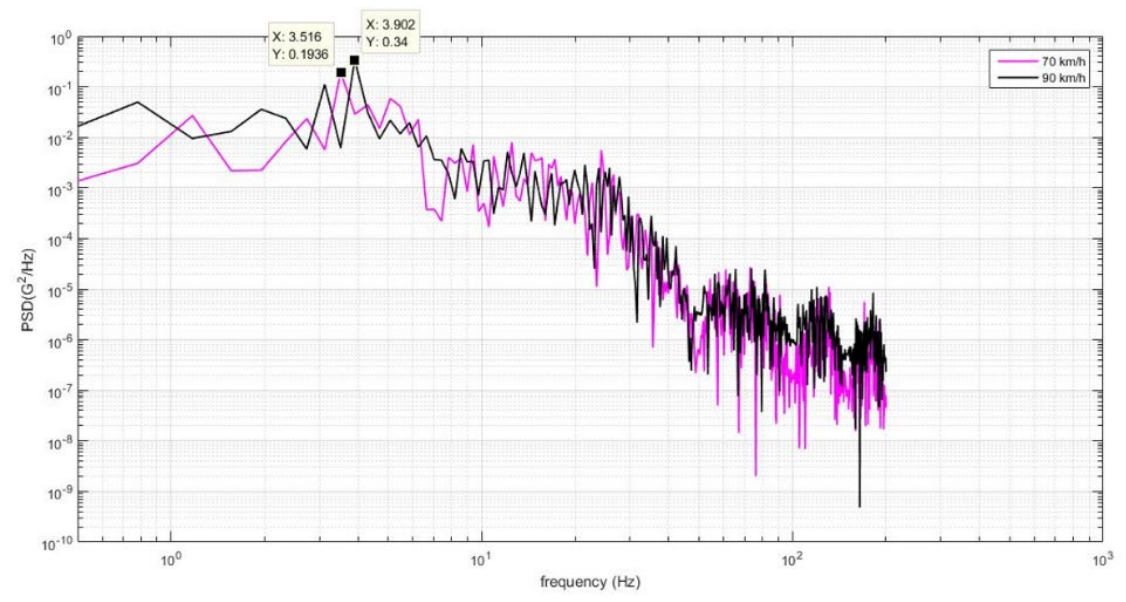

Source: Elaborated by the authors (2019). 
The maximum PSD values and the corresponding frequency for 5 samples were measured in each road presented in Table 2 (at $90 \mathrm{~km} / \mathrm{h}$ speed on route 2 ). The results indicated that the road quality had affected the vibration levels of the truck in such a way that the peak PSD value obtained on highways was lower than that of the ones of the local roads.

Table 2. Peak PSD values and corresponding frequency measured on the roads.

\begin{tabular}{cccc}
\hline Road type & Sample & PSD $_{\text {peak }}\left(\mathbf{G}^{2} / \mathbf{H z}\right)$ & Frequency. peak $(\mathbf{H z})$ \\
\hline \multirow{3}{*}{ Local } & 1 & 0.472 & 3.90 \\
& 2 & 0.717 & 4.29 \\
& 3 & 0.287 & 4.68 \\
& 4 & 0.340 & 3.12 \\
& 5 & 0.516 & 4.29 \\
Highway & 1 & 0.179 & 5.46 \\
& 2 & 0.231 & 3.90 \\
& 3 & 0.152 & 3.90 \\
& 4 & 0.142 & 3.77 \\
& 5 & 0.073 & 6.25 \\
\hline
\end{tabular}

Source: Elaborated by the authors (2019).

Figure 11 shows the PSD diagram for the data of sample 1, and Figure 12 shows the average PSD spectrums for 5 samples on roads. The results presented in mentioned figures were similar to the ones presented in prior studies (PRETORIUS; STEYN, 2012), which specified that the lower value of $P S D_{\text {peak }}$ was found on the highway roads.

Figure 11 - The PSD spectrums for the truck's vibration level in a vertical direction on the local and highway road at $90 \mathrm{~km} / \mathrm{h}$ speed on the rear-down location of truck 2 .

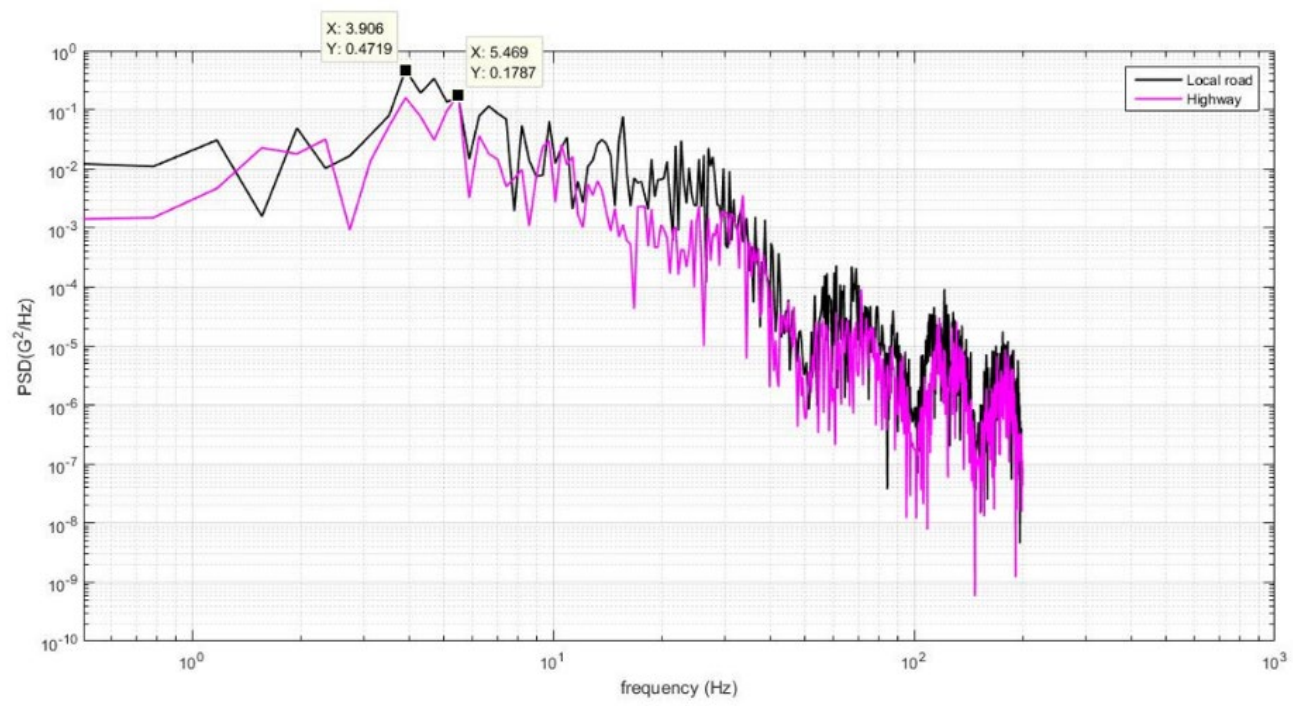

Source: Elaborated by authors (2019). 
Figure 12 - Average PSD spectrums for the truck's vibration levels in a vertical direction on the local and highway roads at $90 \mathrm{~km} / \mathrm{h}$ speed on the rear-down location of truck 2 .

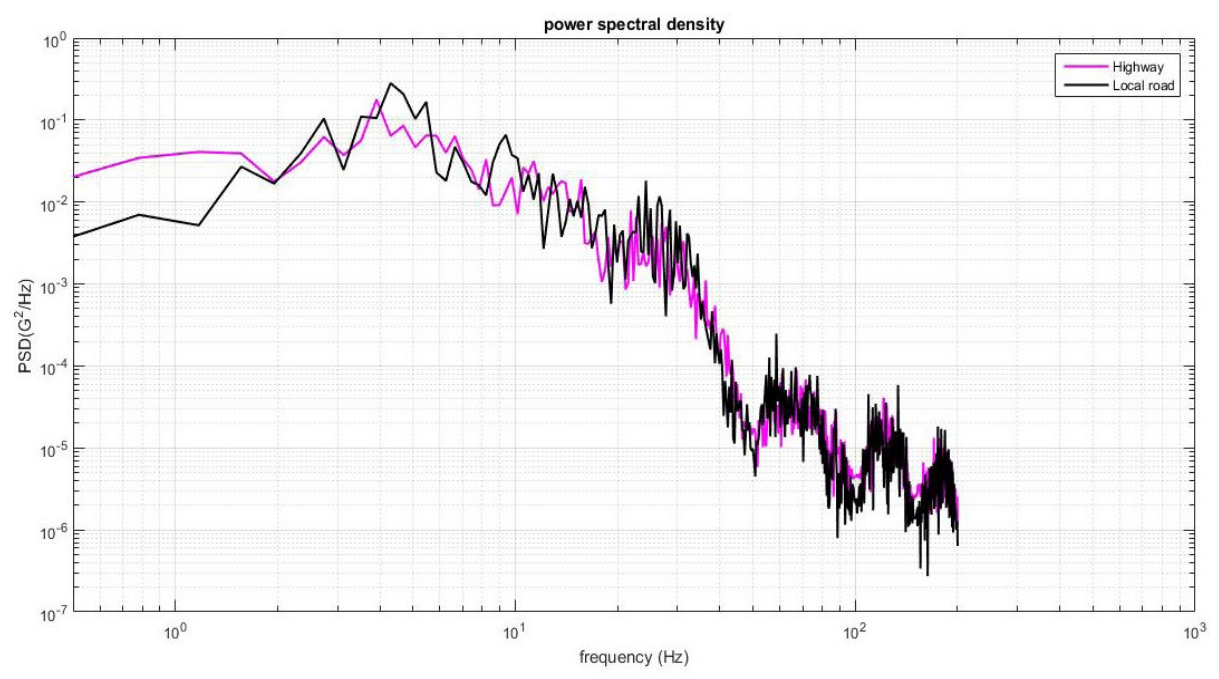

Source: Elaborated by authors (2019).

For a better comparison, the PSD spectrums were smoothed in MATLAB and compared to the ASTM D 4728 standard (FIGURE 13). Testing transport vibration simulation in Iran by applying some globally standardized test protocols like ASTM, ISTA, and JIS makes it difficult to arrive at the optimal cushion-packaging design of agriculture products. The PSD levels of the truck in both the roads type in Iran were higher in 1 to $35 \mathrm{~Hz}$, and lower in 35 to $200 \mathrm{~Hz}$ to the ASTM 4728 standard, relatively. This means that the low frequencies must be considered, and PSD spectrums that are derived from truck transport must be used as a reference in vibration simulation in terms of roads. However, the truck's vibration levels measured in transportation often differ from the indicated standard PSD levels. Therefore, accurate information about the roads and transport conditions of each region helps packaging designers to produce a more precise simulation of the actual condition.

Figure 13 - Smoothed PSD spectrums for the truck's vibration level in a vertical direction on the local road and highway at $90 \mathrm{~km} / \mathrm{h}$ speed on the rear-down location of truck 2 in comparison to ASTM D 4728 standard.

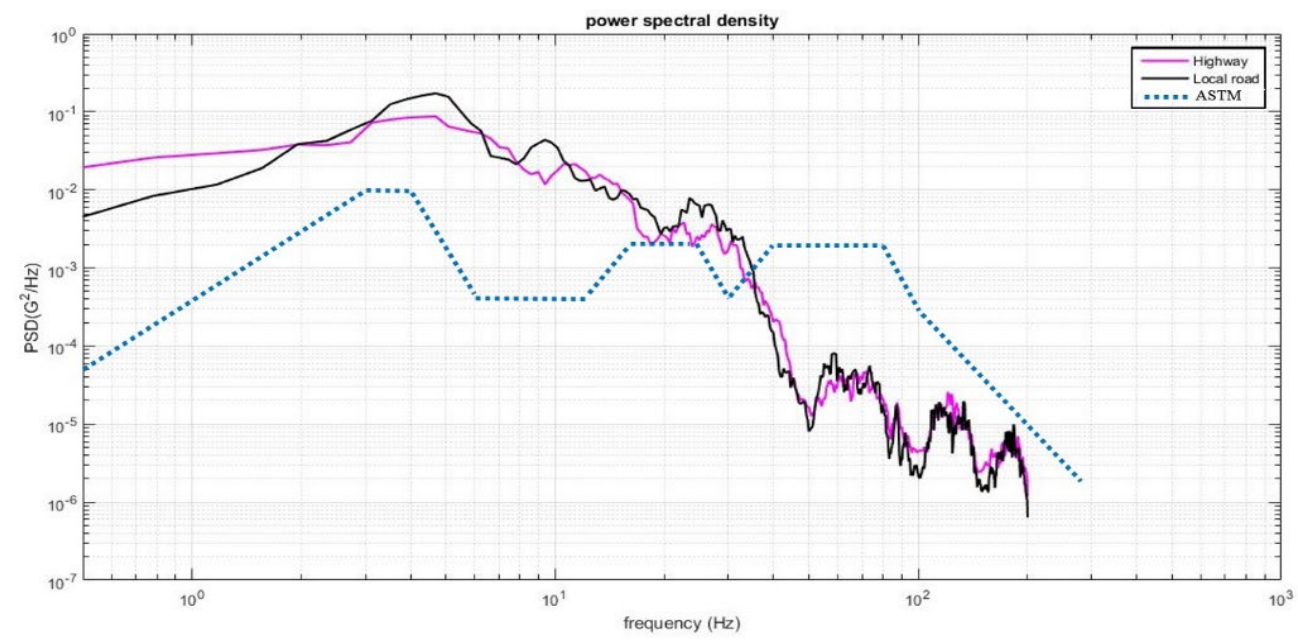

Source: Elaborated by authors (2019). 


\section{Predominant frequency of truck's vibration levels and $\mathrm{RMS}_{\mathrm{G}}$ in Iran roads}

Improved packaging techniques are effective in reducing mechanical damage while transporting fruit to distant cities and markets (SINGH et al., 2014). The damage can be minimized by identifying the type of forces and vibrations to optimally design the packages, proper package management, and proper placement method in the vehicle. On the one hand, lower packaging leads to more damage; but on the other, too much packaging is not environmentally friendly, so an accurate understanding of the vibration levels is essential for designers to choose the best packaging conditions (VIGNEAULT et al., 2009).

The amount of acceleration at the reardown location with the highest vibration levels was measured and recorded to obtain the predominant frequency of vibration on the truck bed. Table 3 presents three peak values of PSD spectrums for each truck recorded in the transportation on two road conditions. Four samples of data were selected from the studied routes. It should be considered that in transportation, the truck speed is controlled by the driver according to the road conditions; therefore, the data represents the vibration levels of the truck that occurred in transport at speed of $70-90 \mathrm{~km} / \mathrm{h}$.

Table 3 - Three peak values of PSD $\left(G^{2} / \mathrm{Hz}\right)$ spectrums on the Iran roads in transportation (70 to $90 \mathrm{~km} / \mathrm{h}$ ).

\begin{tabular}{|c|c|c|c|c|c|c|c|c|}
\hline Road type & Truck & Test & Freq $_{1}{ }^{a}$ & $\mathrm{PSD}_{\mathrm{Max}{ }^{\mathrm{b}}}$ & Freq $_{2}{ }^{a}$ & $\mathrm{PSD}_{\operatorname{Max2}}{ }^{\mathrm{b}}$ & Freq $_{3}{ }^{a}$ & $\mathrm{PSD}_{\operatorname{Max}{ }^{\mathrm{b}}}$ \\
\hline \multirow{12}{*}{ Local } & 1 & 1 & 4.297 & 0.062 & 5.078 & 0.044 & 1.953 & 0.029 \\
\hline & & 2 & 3.516 & 0.161 & 2.344 & 0.060 & 20.313 & 0.034 \\
\hline & & 3 & 4.297 & 0.050 & 3.125 & 0.038 & 2.344 & 0.032 \\
\hline & & 4 & 3.906 & 0.318 & 4.688 & 0.113 & 2.734 & 0.045 \\
\hline & 2 & 1 & 4.297 & 0.717 & 2.734 & 0.263 & 3.516 & 0.113 \\
\hline & & 2 & 3.906 & 0.472 & 4.688 & 0.335 & 5.469 & 0.162 \\
\hline & & 3 & 4.688 & 0.287 & 5.469 & 0.246 & 3.516 & 0.164 \\
\hline & & 4 & 5.078 & 0.299 & 3.906 & 0.138 & 7.031 & 0.120 \\
\hline & 3 & 1 & 3.512 & 0.168 & 1.171 & 0.081 & 4.683 & 0.051 \\
\hline & & 2 & 3.906 & 0.245 & 2.734 & 0.129 & 4.688 & 0.101 \\
\hline & & 3 & 3.906 & 0.129 & 2.734 & 0.103 & 6.250 & 0.053 \\
\hline & & 4 & 3.906 & 0.388 & 1.953 & 0.031 & 7.031 & 0.020 \\
\hline \multirow{12}{*}{ Highway } & 1 & 1 & 3.906 & 0.423 & 9.766 & 0.078 & 8.594 & 0.066 \\
\hline & & 2 & 3.846 & 0.214 & 16.026 & 0.101 & 18.590 & 0.086 \\
\hline & & 3 & 3.516 & 0.237 & 1.953 & 0.139 & 2.734 & 0.116 \\
\hline & & 4 & 3.516 & 0.335 & 0.391 & 0.289 & 5.469 & 0.233 \\
\hline & 2 & 1 & 3.774 & 0.142 & 1.887 & 0.136 & 6.604 & 0.081 \\
\hline & & 2 & 3.906 & 0.231 & 2.734 & 0.15 & 5.859 & 0.087 \\
\hline & & 3 & 3.906 & 0.152 & 5.859 & 0.148 & 3.125 & 0.135 \\
\hline & & 4 & 5.469 & 0.179 & 3.906 & 0.159 & 6.25 & 0.036 \\
\hline & 3 & 1 & 2.732 & 0.119 & 5.463 & 0.042 & 3.902 & 0.041 \\
\hline & & 2 & 4.688 & 0.239 & 3.125 & 0.203 & 3.906 & 0.124 \\
\hline & & 3 & 4.683 & 0.093 & 3.122 & 0.075 & 5.463 & 0.053 \\
\hline & & 4 & 3.512 & 0.151 & 4.683 & 0.091 & 2.341 & 0.039 \\
\hline
\end{tabular}

a Peak value of PSD spectrum frequency; ${ }^{\text {b }}$ Peak value of PSD spectrum

Source: Elaborated by the authors (2019). 
Figure 14 shows the column chart of the number of peak PSD values (TABLE 3) found in the specified frequency ranges. The results showed that the highest PSD values were found in the frequency range lower than $6 \mathrm{~Hz}$, and lower intensity vibration was observed in the frequency range higher than $10 \mathrm{~Hz}$. The frequency range of 3 to $4 \mathrm{~Hz}$ was obtained as the predominant frequency of vibration for both the local and highway roads, respectively. This result agrees with the ones of previous studies. Hinsch et al. (1993) found that the highest PSD levels were in the range of $3.5 \mathrm{~Hz}$ in semi-trailers with steel spring suspension systems. Zhou and Wang (2018) found that the PSD peak frequencies in the low-frequency region $(1-10 \mathrm{~Hz})$ occurred at about 3 to $4 \mathrm{~Hz}$. So, the packaging designers should concentrate on methods of reducing the trucks' vibration levels reaching the packages, particularly at frequencies range of 1 to $6 \mathrm{~Hz}$.

The RMS values of acceleration in the reardown location of the truck for routes 1 and 3 were 0.241 and 0.231 in the longitudinal direction, 0.393 and 0.419 in the transverse direction, 0.695 and 0.614 in the vertical direction respectively. Hence, it can be concluded that the vertical vibration level of trucks is more important than the lateral and longitudinal vibrations when optimizing packaging conditions, which should be, therefore considered in future lab simulations. The values of $\mathrm{RMS}_{\mathrm{G}}$ for route 2 in the longitudinal, transverse and vertical directions were $0.489,0.667$ and, 0.850, respectively, which have higher values than routes 1 and 3 . This difference is due to the use of light trucks and less cargo weight (4 tons) than two other trucks used in routes 1 and 3 (heavy trucks). In the laboratory studies, the amount of acceleration on the heavy truck beds on the country's roads can be considered $0.654 \mathrm{G}$ (by calculating the average $\mathrm{RMS}_{\mathrm{G}}$ values of vertical acceleration in routes 1 and 3 ). In the previous researches around the world, vertical $\mathrm{RMS}_{G}$ for vehicles with spring suspension was equal to $0.161 \mathrm{G}$ for India (SINGH et al., 2007), $0.55 \mathrm{G}$ for Brazil (RISSI et al., 2008), 0.238 G for Thailand (CHONHENCHOB et al., 2010), 0.20 G for Spain (GARCIA-ROMEU-MARTINEZ; SINGH; CLOQUELL-BALLESTER, 2008), 0.33 G for China (ZHOU; WANG, 2018), and 0.31 G for Korea (PARK; CHOI; JUNG, 2020).

Comparing the average $\mathrm{RMS}_{\mathrm{G}}$ found with the ones mentioned in previous studies showed that the vertical vibration levels of the truck in Iran are higher than in most mentioned countries. Apart from driving quality, all of these results can be explained by the type of suspension system, amount of load, road quality, and traffic in the country. The accelerations increase with higher driving speeds, lighter loads, and bad road conditions (RISSI et al., 2008). Earlier studies indicate more severe vibration in trucks with leaf-spring suspension than in trucks with airride suspension (GARCIA-ROMEU-MARTINEZ; SINGH; CLOQUELL-BALLESTER, 2008). Singh and Marcondes (1992) reported that the vertical vibration levels in truck beds were higher than the lateral and longitudinal ones. The highest amount of acceleration occurred in the packages located on the top of the column at the rear of the truck. Therefore, the high driving skills, full-capacity truck loading, proper route selection, and the use of air ride trucks can be effective in reducing vibration levels and the damage caused by them.

The presented findings are crucial to achieving optimal fruit packaging using a lab vibrating simulator for further research on packaged produce. Laboratory studies on apples showed that in all packaging methods used, the frequency of $8.2 \mathrm{~Hz}$ and the vibration acceleration of $0.63 \mathrm{G}$ led to the greatest damage to the crop (VURSAVUŞ; ÖZGÜVEN, 2004). The vibration bruising of the apple in the transport was studied, and a laboratory vibration simulator was used to apply controlled vibrations. The results showed that the vibrational combination of 13 $\mathrm{Hz}$ and $0.7 \mathrm{G}$ causes the most damage to apples 
Figure 14 - Some PSD peaks were found according to the special frequency ranges at the Iran roads.
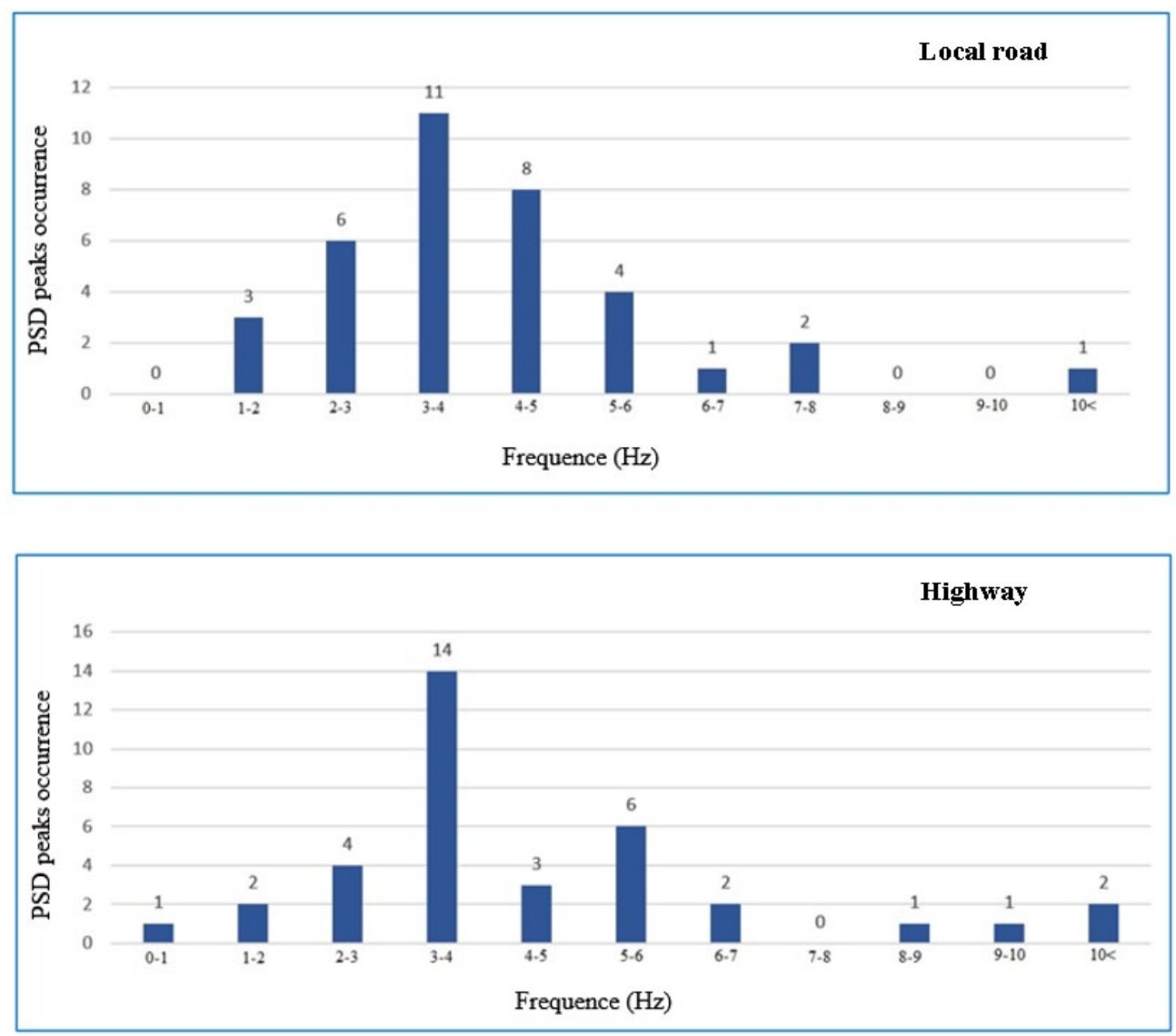

Source: Elaborated by the authors (2019).

(ROSTAMPOUR; MOTLAGH, 2018). The proximity of the vibration acceleration of the truck bed on the country's roads to the vibration acceleration that causes the most damage to the apple highlights the need to design the box and upgrade the packaging to reduce vibrations and acceleration on transportation. Thus, potential future works are lab simulations, optimizations of packages, and the development of a real-time vibration monitoring system. The real-time vibration monitoring system in fresh produce transportation can also be developed as a driver awareness system to choose the right speed. For this purpose, a range of acceleration can be set as acceptable values, and if the acceleration exceeds the specified values, an alarm system should be activated leading to a speed reduction by the driver. Additionally, the findings and the methodology are of high interest to improve driving behavior, packaging materials, reduce fruit damage, smart transportation, real-time computation on big data, multi-sensor-based systems, and other related domains.

\section{Conclusions}

The results found in the present study can be used to simulate the transport conditions by programmable vibration simulators to reproduce the vibration conditions for package testing in Iran. And the findings are of high interest in order to improve packaging design, reduce fruit damage, maintain shelf life, smart transportation, and related industries. 


\section{Acknowledgments}

The authors thank the Department of Biosystems Engineering, University of Tabriz, Tabriz, Iran for financial support.

\section{References}

AKYILDIZ,I.F.;WEILIAN,S.;SANKARASUBRAMANIAM, Y.; CAYIRCI, E. A survey on sensor networks. IEEE Communications Magazine, v. 40, n. 8, p. 102-114, 2002.

AMER EISSA, A. H.; ALBALOUSHI, N. S.; AZAM, M. M. Vibration analysis influence during crisis transport of the quality of fresh fruit on food security. Agriculture Engineering International CIGR Journal, v. 15, n. 3, p. 181-190, 2013.

BACHMANN, J.; EARLES, R. Postharvest handling of fruits and vegetables. Appropriate Technology Transfer for Rural Areas, p. 1-19, 2000.

BOLLEN, A.; TIMM, E.; RUE, B. D. Relation of individual forces on apples and bruising during orchard transport of bulk bins. Agriculture Engineering International, v. 17, n. 2, p. 193200, 2001.

CHONHENCHOB, V.; SINGH, S. P.; SINGH, J. J.; SITTIPOD, S.; SWASDEE, D.; PRATHEEPTHINTHONG, S. Measurement and analysis of truck and rail vibration levels in Thailand. Packaging Technology Science, v. 23, 2, p. 91-100, 2010.

CHONHENCHOB, V.; SITTIPOD, S.; SWASDEE, D.; RACHTANAPUN, P.; SINGH, S.; SINGH, J.A. Effect of truck vibration during transport on damage to fresh produce shipments in Thailand. Industrials Technology, v. 3, p. 27-38, 2009.
FERNANDO, I.; FEI, J.; STANLEY, R. Measurement and analysis of vibration and mechanical damage to bananas during longdistance interstate transport by multi-trailer road trains. Postharvest Biology and Technology, v. 158, p. 1109-77, 2019.

GARCIA-ROMEU-MARTINEZ, M. A.; SINGH, S. P.; CLOQUELL-BALLESTER, V. A. Measurement and analysis of vibration levels for truck transport in Spain as a function of payload, suspension and speed. Packaging Technology Science, v. 21, n. 8, p. 439-451, 2008.

GEBRESENBET, G.; ARADOM, S.; BULITTA, F. S.; HJERPE, E. Vibration levels and frequencies on vehicle and animals during transport. Biosystems Engineering, v. 110, n. 1, p. 1019, 2011.

HINSCH, R.; CRAIG, W.; SLAUGHTER, D.; THOMPSON, J. Vibration of fresh fruits and vegetables during refrigerated truck transport. American Society of Agriculture and Engineering, v. 36, n. 4, p. 1039-1042, 1993.

ISHIKAWA, Y.; KITAZAWA, H.; SHIINA, T. Vibration and shock analysis of fruit and vegetables transport-Cherry transport from Yamagata to Taipei. Japan Agriculture Research Quarterly, v. 43, n. 2, p. 129-135, 2009.

LU, F.; ISHIKAWA, Y.; KITAZAWA, H.; SATAKE, $T$. Effect of sampling parameters on shock and vibration levels in truck transport. 17th IAPRI World Conference Packaging, p. 129-135, 2010a.

LU, F.; ISHIKAWA, Y.; KITAZAWA, H.; SATAKE, T. Effect of vehicle speed on shock and vibration levels in truck transport. Packaging Technology Science, v. 23, n. 2, p. 101-109, 2010b. 
LU, F.; ISHIKAWA, Y.; SHIINA, T.; SATAKE, T. Analysis of shock and vibration in truck transport in Japan. Packaging Technology Science, v. 21, n. 8, p. 479-489, 2008.

PARK, J.; CHOI, S.; JUNG, H. M. Measurement and Analysis of Vibration Levels for Truck Transport Environment in Korea. Applied Science, v. 10, p. $6754,2020$.

PATERNOSTER, A.; VANLANDUIT, S.; SPRINGAEL, J.; BRAET, J. Vibration and shock analysis of specific events during truck and train transport of food products. Food Packaging Shelf Life, v. 15, p. 95-104, 2018.

PRETORIUS, C.; STEYN, W. J. Influence of road roughness on the transportation of fresh produce. 31st South African Transportation Conference, v. 9, p. 142-153, 2012.

RANATHUNGA, C.; JAYAWEERA, H.; SURAWEERA, S.; WATTAGE, S.; RUVINDA, K.; ARIYARATNE, T. Vibration effects in vehicular road transportation. Conference: Proceedings of the Technical Sessions, v. 26, p. 9-16, 2010.

RISSI, G. O.; SINGH, S. P.; BURGESS, G.; SINGH, $J$. Measurement and analysis of truck transport environment in Brazil. Packaging Technology Science, v. 21, n. 4, p. 231-246, 2008.

ROSTAMPOUR, V.; MOTLAGH, A. M. Evaluation of the bruising susceptibility of apple in transport conditions. Bulgarian Journal of Agricultural Science, v. 24, n. 5, p. 902-908, 2018.

RUIZ-GARCIA, L.; BARREIRO, P.; RODRIGUEZBERMEJO, J.; ROBLA, J. I. Monitoring the intermodal, refrigerated transport of fruit using sensor networks. Spanish Journal of Agriculture Research, v. 5, n. 2, p. 142-156, 2007.
SINGH, P.; SINGH, S.; SINGH, B.; MISHRA, D. Standardization of Packaging for Transportation of Guava Fruits. International Journal Emerging Technology Advanced E., v. 4, n. 8, p. 541-546, 2014.

SINGH, S. P.; ANTLE, J. R.; BURGESS, G. G. Comparison between lateral, longitudinal, and vertical vibration levels in commercial truck shipments. Packaging Technology Science, v. 5, n. 2, p. 71-75, 1992.

SINGH, S. P.; MARCONDES, J. Vibration levels in commercial truck shipments as a function of suspension and payload. Journal of Testing and Evaluation, v. 20, n. 6, p. 466-469, 1992.

SINGH, S. P.; SANDHU, A. P. S.; SINGH, J.; JONESON, E. Measurement and analysis of truck and rail shipping environment in India. Packaging Technology Science International Journal, v. 20, n. 6, p. 381-392, 2007.

SPRINGAEL, J.; PATERNOSTER, A.; BRAET, J. Reducing postharvest losses of apples: Optimal transport routing (while minimizing total costs). Computers and Electronics in Agriculture, v. 146, p. 136-144, 2018.

TABATABAEKOLOOR, R.; HASHEMI, S.; TAGHIZADE, G. Vibration Damage to Kiwifruits during Road Transportation. International Journal of Agriculture Food Science, v. 4, n. 5, p. 467-474, 2018.

VIGNEAULT, C.; THOMPSON, J.; WU, S.; HUI, K. C.; LEBLANC, D. Transportation of fresh horticultural produce. Postharvest Technology of Horticultural Crops, v. 2, p. 1-24, 2009. 
VURSAVUŞ, K.; ÖZGUVEN, F. Determining the effects of vibration parameters and packaging method on mechanical damage in golden delicious apples. Turkish Journal of Agriculture Forestry, v. 28, n. 5, p. 311-320, 2004.

WASALA, W.; DHARMASENA, D.; DISSANAYAKE, T.; THILAKARATHNE, B. Vibration Simulation Testing of Banana Bulk Transport Packaging Systems. Tropical Agriculture Research, v. 26, n. 2, p. 355-367, 2015.

YENGE, G. B.; NIDONI, U. Transportation losses in fresh fig (Ficus Carica $L$ ) fruits. International Journal of Farm Science, v. 4, n. 3, p. 100-109, 2014.

ZHANG, L.; YANG, C.; WANG, Y.; PAN, D.; MENG, X.; TONG, T. Vibration and impact performance tests of cherry tomato transport packages. Transactions China Society Agriculture for Machinery, v. 42, p. 125-130, 2011.

ZHOU, H.; WANG, Z. W. Measurement and analysis of vibration levels for express logistics transportation in South China. Packaging Technology Science, v. 31, n. 10, p. 665-678, 2018.

ZHOU, R.; SU, S.; LI, Y. Effect of transport vibration levels on mechanical damage and physiological responses of Huanghua pears (Pyrus pyrifolia Nakai, cv. Huanghua). Postharvest Biology and Technology, v. 46, n. 1, p. 20-28, 2007. 